lack of supervision. $31 \%$ of schools felt more funding and provision was required in this area.

Limitations The data may be skewed because provision status in non-responders was unknown. The majority of non-responders $(81 \%)$ were primary schools. It is possible they did not respond because they did not have a service.

Conclusion The current mental health provision in schools cannot adequately substitute for a formal Tier 2 CAMHS service. Service provision is not uniform. Some schools had no service at all and some services did not meet Tier 2 criteria because providers were not mental health trained. Lack of skills within the service is worrying, particularly when dealing with depression, which needs adequate risk assessment. A difficult referral process to Tier 3 services may also be a barrier to accessing treatment. Considering the importance of early intervention to prevent significant mental health problems, the lack of good quality services at Tier 2 is concerning.

\section{G505(P) MEDICAL STUDENTS BUYING METHYLPHENIDATE ONLINE}

IJ Lane, ${ }^{2} \mathrm{~F}$ Finlay, ${ }^{2} \mathrm{H}$ Marcer. ${ }^{1}$ Bristol Medical School, University of Bristol, Bristol, UK; ${ }^{2}$ Child Health, Sirona, Bath, UK

\subsection{6/archdischild-2015-308599.458}

Background A study from US found that non-medical use of prescription stimulants in students ranged from $0-25 \%$, and a study from Cambridge University revealed that $10 \%$ of students have taken 'smart drugs.'

Although there are no studies in the UK on the prevalence of Methylphenidate use in medical students, we are aware of this practice first hand. Some report buying Methylphenidate online. Aims/Method We consulted colleagues in the legal profession, GMC guidelines, police and pharmacy to clarify implications of buying Methylphenidate online.

Results Methylphenidate and the law

Methylphenidate is a class B drug controlled drug.

It is unlawful to have a controlled drug in your possession unless you have authorisation in the form of a licence, eg. prescription.

The actual act of buying methylphenidate online is not illegal under the Misuse of Drugs Act but you commit an offence once you have the drug in your possession.

Possession could lead to up to 5 years in prison and an unlimited fine.

GMC Guidance The GMC has clear guidance on self-prescribing.

You must avoid prescribing for yourself or anyone with whom you have a close personal relationship.

You must not prescribe controlled medicines for yourself unless no other person with the legal right to prescribe is available to assess and prescribe without delay, which would put your life/health at risk, or cause unavoidable pain or distress.

Methylphenidate does not fit into this category. Students found to be self-prescribing could face a fitness to practice hearing/professional conduct meeting.

Conclusion There is anecdotal evidence that medical students in the UK are taking cognitive enhancement drugs.

The GMC has clear guidance on self prescribing - the offlicense use of Methylphenidate as a study aid would not be accepted.

Some are buying it from unregulated pharmacies online possession is illegal as Methylphenidate is a class B drug.
Students should be made aware of the risks so that they do not inadvertently compromise their health or future professional careers.

Universities should ensure that the issue of online purchasing and self medication, is explicitly discussed with medical students as part of their curriculum.

\section{G506(P) CRY A LITTLE TENDERNESS? DO DOCTORS CRY AND IS THIS ACCEPTABLE?}

EZA Bassett, F Finlay. Community Child Health, Sirona Health Care, Bath, UK

\subsection{6/archdischild-2015-308599.459}

Aims How common is it for doctors to cry? Do paediatricans cry as a sign of humanity and an expression of compassion? Is crying a weakness, a demonstration of incompetence? Or, in the right circumstance, does it enhance the doctor-patient relationship? A review of the literature will aim to answer these questions.

Methods Literature search

Results Doctors do cry. Sung ${ }^{1}$ found 69\% of medical students and $74 \%$ of interns cried at work. Wagner ${ }^{2}$ reported $57 \%$ of doctors, $31 \%$ of medical students and $76 \%$ of nurses cried. Women were more likely than men to cry. ${ }^{1,2}$ Medical students reported the highest negative social consequence of crying $^{2}$ stating it was often viewed as a sign of weakness. ${ }^{3}$ But views on crying are debated, ${ }^{4}$ opinions ranging from enthusiastic advocacy, guarded acceptance, ${ }^{5}$ outright rejection and condemnation. ${ }^{4}$

The concept of the detached physician ${ }^{6,7}$, remains alive and well. On the BMA Blog ${ }^{8}$ doctors debate learned behaviours to distance themselves from emotionally distressing situations. ${ }^{9}$ Others question if this is healthy ${ }^{4,8,9,10}$ debating if it is possible to have compassion, without emotion. The Francis Report $2013^{16}$ highlights the need for Compassion in Practice. ${ }^{17}$

Patients expect empathy and the demonstration of emotion by their doctor ${ }^{11,12}$ but only up to a point. ${ }^{13}$ Hojat $^{14}$ states it contributes to a better doctor-patient relationship with Anderson ${ }^{15}$ writing there is nothing wrong with a doctor who makes a patient feel nurtured while still being professional and appropriate.

Conclusion Humanity is the cornerstone of medicine. Depersonalization, with physicians distancing themselves from potentially emotionally challenging situations threatens the core principles of the profession. As paediatricians we need a balanced mix of rationality and compassion with an attitude of humility. We need to teach medical students how to break bad news, cope with baring witness to the dying process, and support those caught in the aftermath. We need to continue this education throughout medical careers while providing physicians with the resources to seek support as they need it.

\section{REFERENCES}

1 Sung $A D$, Collins ME, Smith AK, et al. Crying: experiences and attitudes of 3rd year medical students and interns. Teach Learn Med. 2009; 21(3):180-7

2 Wanger RE, Hexel M, Bauer WW, et al. Crying in hospital: a survey of doctors, nurses and medical students experience and attitudes. Med J Aust. 1997;166(1): 13-6

3 Angoff. A piece of my mind: crying in the curriculum. JAMA 2001; 286(9): 1017-8

4 Pruthi S, Goel A. Doctors do cry. Indian J Med Ethics 2014; 11(4):249-251

5 Majhail NS, Warlick ED. To cry or not to cry? physicians emotions at the bedside. Minn Med. 2011; 94(1):40-42

6 Sir William Osler, 1849 1919: A selection for medical students

7 Lief and Fox. Training for "detached concern" in medical students. The psychological basis of medical practice. New York: Harper and Row, 1963: 12-35 
8 Dawlatly. When did you last cry over a patient? BMJ Blog 18/03/2014

9 Horn. "I must not burst into tears in front of patients". What physicians can learn from ethnographers when dealing with emotion. Ethox.ox.ac.uk

10 Wright JG, Khetani N, Stephens D. Burnout among faculty physicians in an academic health science centre. Paediatr Child Health 2001; 16(7):409-13

11 Rosenblum JL. Why I still cry. Share a young internist's reflection on death of a patient at the end of a long day. Med Econ. 2002; 79(13):65-66

12 Krauser PS. A piece of my mind. Tears. JAMA 1989; 261(24):3612

13 Friedrichsen MJ, Strang PM, Carlsson ME. Breaking bad news in the transition from curative to palliative cancer care - patients' view of doctor giving information. Support Cancer Care 2000; 8:472-478

14 Hojat M, Louis DZ, Markham FW, et al. Physicians' empathy and clinical outcomes for diabetic patients. Acad Med. 2011; 86(3):359-64

15 Anderson. Stand by her: A breast cancer guide for men. 2009

16 Francis. Report of the Mid Staffordshire NHS Foundation Trust Public Enquiry, London: The Stationary Office, 2013

17 Cummings and Bennett. Compassion in practice, NHS England, 2013

\section{George Still Forum}

\section{G507 RELATIONSHIP DEVELOPMENT INTERVENTION; A DEVELOPMENTAL PERSPECTIVE TO AUTISM MANAGEMENT}

${ }^{1}$ DN Patil, ${ }^{2}$ ACB Setti. ${ }^{1}$ Department of Paediatrics and Child Health, Hwyel Dda University NHS Trust, Withybush General Hospital, Haverfordwest, UK; ${ }^{2}$ Child Health Centre, Hywel Dda NHS University NHS Trust, Withybush General Hospital, Haverfordwest, UK

10.1136/archdischild-2015-308599.460

Introduction/Aim The aim of this paper is to present the experiences of two familes of children with autism spectum disorder (ASD) using a particular intervention.

The deficits of individuals with ASDs can be divided into homogeneous "primary" deficits, which define the disorder, and heterogeneous "secondary" deficits, which may or may not be present. Primary deficits reflect poor development of dynamic neural functioning and the failure to develop dynamic intelligence.

NICE Guidelines The management and support of children and young people on the ASD(August 2013) recommends that interventions for core ASD features include training of parents, caregivers, and teachers to increase joint attention and reciprocal communication using video-feedback methods appropriate to the child's developmental level.

One such intervention, Relationship Development Intervention (RDI), uses the principle of typical development of Dynamic Intelligence via Guided Participation relationship, which either never gets to develop or gets disrupted early in the development of a ASD child.(development psychology research)

RDI is implemented through intensive parent education to reconstruct their natural "guide" relationship from a developmental perspective, modelling and role-playing, regular videotape review of parent-child performance, and school staff training.

Methods This intervention has been used on my own son for $3 \frac{1}{2}$ years and another child with an ASD for 1 year. They were followed through regular videos and Relationship Development Assessment (RDA) of the child and parents every 6 months.

RDA consists of a semi-structured observational assessment (RDA-RV) focusing on three interpersonal parent-child processes: shared attentional focus, ability to co-regulate an interaction, and ability to share emotional experiences.

Results Both families showed Improvement in their child's ability to interact and engage, accept and adjust actions with parent modelling and pace adjustment, understand changes and variations with continuity, and co-ordinate their actions with others.

After RDI for $3 \frac{1}{2}$ years One child was able to 1) understand and use nonverbal cues, gestures, and facial expressions; 2) explore new situations and activities, participating with other adults to learn; and 3) handle group activities/peer games like almost any normal child.

Conclusions The results show overall improvements in functioning related to ASDs. An examination of the literature reveals a growing body of empirical evidence and best practice recommendations supporting the practices embedded in RDI.

\section{G508 ARE PAEDIATRIC SERVICES BETTER GEARED UP THAN CAMHS TO MONITOR PATIENTS ON STIMULANT MEDICATION?}

S Nelapatla, V Pulla. Paediatric Unit, North Lincolnshire and Goole NHS Foundation Trust, Scunthorpe, UK

\subsection{6/archdischild-2015-308599.461}

Stimulant medications are widely used to control symptoms of Attention Defict Hypercativty Disorder in children and NICE has issued comprehensive guidelines in 2008 about diagnostic criteria based on DSMIV and monitoring of patients on medication

RCPSYCH under QIP through PRESCRIBING OBSERVATORY FOR MENTAL HEALTH -UK (POMH) undertook a national audit - topic 13a "prescribing for ADHD medication" 2013.

Audit tool, sampling options poster and participation were sent to POMH lead contact. Data was collected over a period of one montha and entered on line. data was anaylysed over 6 month period and resuls were published. It measured 6 standards Heart rate, BP, Height, Weight, Cardivascular risk assessment and substance misuse risk before starting treatment, 3 months after and over a year

There were 5479 patients in 48 Trusts under 370 clinical teams. There were 429 Paediatric patients in the sample treated by paediatricians. 3737 by CAMHS teams and 1313 adult patients. Children aged 13-8 were the largest group, $83 \%$ were male, $80 \%$ were caucasian. commonest co morbidities: $25 \%$ had sleep disorder, $23 \%$ pervasive developmental disoder. Adults had $25 \%$ had mood, personality and stress disorder. $30 \%$ had no co morbid disoder.

Our Trust compliance was highest in the sample with $100 \%$ in all the 6 standards before and 3 months after starting treatment and $88 \%$ over the year.

We provide ADHD service in DGH setting and treat $\sim 200$ patients per year. We run 4 dedicated clinics a month and have designed specific templates for initial and fup clinics to capture the data and paediatrics is more failiar in plotting growth charts, measuring BP and performing physical examination than CAMHS colleagues which has helped us to do well in this audit. A well focussed team with limited resources can provide high quality care and this has been re inforced by a recent service user survey.

It is unclear from this audit what percentage of services are provided in UK by paediatricians and CAMHS. As the project was initiated by RCPSYCH Paediatricians providing a service were probably not aware hence less data input. 